\title{
HACIA UNA NUEVA CRÍTICA MATERIALISTA: REALISMO ARGENTINO RECIENTE Y LO REAL LACANIANO ${ }^{1}$
}

\author{
Towards a new materialist criticism: Recent Argentinian realism and the \\ Lacanian Real
}

David Parra*

\begin{abstract}
RESUMEN
Este artículo propone una lectura materialista del género realista, tomando como base la teoría del lenguaje de Jacques Lacan (1901-1981), y sus reelaboraciones (Žižek 1989, Eyers 2011 y Kornbluh 2017). Se discutirá su extendida clasificación como "postestructuralista", tomando como eje el carácter materialista de la noción de lo Real. Considerando la influencia predominante del postestructuralismo en la crítica literaria, este distanciamiento teórico tiene consecuencias políticas, estéticas y literarias relevantes que permitan rescatar al realismo del anticuario de los géneros literarios. Para ejemplificar, se analizará un corpus de tres obras argentinas de las últimas décadas: Este-oeste de Martín Rejtman, La villa de César Aira y Rabia de Sergio Bizzio.
\end{abstract}

Palabras clave: realismo literario, materialismo, psicoanálisis lacaniano, lo Real, Martín Rejtman, César Aira, Sergio Bizzio.

\footnotetext{
${ }^{1}$ Parte de este artículo es resultado del Proyecto Fondecyt Regular $N^{\circ} 1160230$ titulado "Patrimonialismo y casuismo en el ensayo literario hispanoamericano 1930-2015. Cohesiones simbólicas negativas en su enunciación y figuras textuales" que dirige Roberto Hozven como investigador responsable.

* Académico de la Facultad de Letras, Pontificia Universidad Católica de Chile, Santiago, Chile. Correo electrónico: diparra@uc.cl
}

Artículo recibido el 13 de agosto de 2018. Aceptado el 6 de noviembre de 2018. 


\begin{abstract}
This article proposes a materialistic approach to the genre of realism, based on Jacques Lacan's theory of language and its reworkings (Žižek 1989, Eyers 2011 and Kornbluh 2017). Its extended classification as "poststructuralist" will be discussed, taking as a central point the materialist character of the notion of the Real. Considering the predominant influence of poststructuralism in literary criticism, this theoretical distancing has relevant political, aesthetic and literary consequences that make possible a rescue of the realism from the antiquarian of literary genres. To exemplify, a corpus of three Argentine works of the last decades will be analyzed: Este-Oeste by Martín Rejtman, La villa by César Aira and Rabia by Sergio Bizzio.
\end{abstract}

Keywords: Literary realism, materialism, Lacanian psychoanalysis, the Real, Martín Rejtman, César Aira, Sergio Bizzio.

\title{
1. Introducción
}

La gran crisis del lenguaje que determina el paso del siglo XIX al XX está lejos de ser una temática superada. Desde Nietzsche, por ejemplo, la filosofía ya no podrá pensar el estatuto de la verdad sin considerar la densidad retórica ${ }^{2}$; con Freud, el lenguaje deja de ser el vehículo transparente de un yo unificado, cuyas fisuras (lapsus, olvidos y síntomas) evidencian “otra escena"3; con Marx, la relación sugerida entre lenguaje, producción e ideología inaugura un nuevo modo de comprender la realidad social ${ }^{4}$. A partir de estas tres grandes heridas lingüísticas que hereda el siglo $\mathrm{XX}$, el pensamiento tendrá

\footnotetext{
2 “¿Qué es verdad, entonces? Un móvil ejército de metáforas, metonimias, antropomorfismos, en breve, una suma de relaciones humanas que han sido realzadas, trasladadas, adornadas poética y retóricamente, y que tras un uso largo le parecen a un pueblo firmes, canónicas y obligatorias: las verdades son ilusiones de las que se ha olvidado que lo son, metáforas que han sido desgastadas por el uso y que han perdido su fuerza sensible, monedas que han perdido su efigie y sólo pueden ser consideradas como metal y ya no como monedas" (Nietzsche 8).

3 "En lo inconsciente anímico, en efecto, se discierne el imperio de una compulsión de repetición que probablemente depende, a su vez, de la naturaleza más íntima de las pulsiones; tiene suficiente poder para doblegar al principio de placer, confiere carácter demoníaco a ciertos aspectos de la vida anímica, se exterioriza todavía con mucha nitidez en las aspiraciones del niño pequeño y gobierna el psicoanálisis de los neuróticos en una parte de su decurso. Todas las elucidaciones anteriores nos hacen esperar que se sienta como ominoso justamente aquello capaz de recordar a esa compulsión interior de repetición" (Freud 238).

4 "El lenguaje es tan viejo como la conciencia: el lenguaje es la conciencia práctica, la conciencia real, que existe también para los otros hombres y que, por tanto, comienza a existir también para mí mismo; y el lenguaje nace, como la conciencia, de la necesidad, de los
} 
que fundar su lugar de operación en el lenguaje mismo. La lingüística, como una ciencia de lenguaje, entregará los materiales para pensar este impasse. Herramienta que el estructuralismo hará suya para fines propios y que el llamado postestructuralismo intentará trascender.

Con el denominado "giro lingüístico" y el postestructuralismo, el realismo literario parece haber quedado relegado a una anécdota en la historia de los géneros literarios. La "crisis de la referencialidad" socavó la ingenua pretensión de representar lo Real en el texto literario. La clásica definición de Realismo: "[...] corriente artística que se ha propuesto como finalidad reproducir la realidad lo más fielmente posible y que aspira al máximo de verosimilitud" (Jakobson 71), se ha hecho totalmente anacrónica. El propio Lacan contribuyó a este sepultamiento: “[...] más allá del realismo que, socialista o no, es siempre un efecto de discurso" (Otros escritos 244). Sin embargo, un impulso de reevaluación del realismo en Argentina en la última década $^{5}$ propone repensar la relación del realismo literario, el lenguaje y la representación ${ }^{6}$.

Fredric Jameson, en un ensayo de la década de los setenta, resume la disputa entre Lukács y Brecht como especie de "retorno de lo reprimido" en el conflicto estético entre realismo y modernismo. A sus ojos, una de las características centrales del realismo es la "[...] reivindicación de un estatus cognitivo a la par que estético" (3). En este sentido, uno de los problemas centrales del realismo como género reside en la forma de experiencia estética que reclama: "[...] una relación vinculante con lo real mismo, es decir, con aquellas esferas de conocimiento y praxis que tradicionalmente habían sido

apremios del intercambio con los demás hombres" (Marx 31).

5 Véase de Sandra Contreras "Discusiones sobre el realismo en la narrativa argentina contemporánea" (2006) y "Cuadernos del Seminario 2: Realismos: cuestiones críticas" (2013). La autora señala: "En su insistencia -seguimos discutiendo, ¡a principios del XXI!, sobre realismo- la confrontación es seguramente un indicio de cuán central o estructurante es el problema en la literatura argentina, de cuánto la define, pero también, y esto me parece todavía más importante, de cuánto interés todavía contiene y suscita una categoría "clásicamente" literaria, del modo en que persiste, en el contexto de nuestra época y su cuestionamiento de la noción misma de literatura" (Contreras, "Discusiones sobre el realismo en la narrativa argentina contemporánea" 2).

${ }^{6}$ Discusión para nada nueva en la historia literaria argentina. Véase "Discusiones en torno al Realismo en las generaciones jóvenes del primer postperonismo" de Diego Poggiese (2009). 
diferenciadas de la esfera de lo estético, con sus juicios desinteresados y su constitución como pura apariencia" (3). Este vínculo con "lo real mismo" es particularmente problemático, pues si se enfatiza demasiado la función cognitiva, se rechaza con demasiada facilidad el carácter ficticio del discurso estético, es decir, pierde relevancia, mientras que si se afirma el polo contrario-el "efecto de realidad" de Barthes ${ }^{7}$-se "[...] tiende a transformar subrepticiamente la 'realidad' del realismo en apariencia, y a minar esa afirmación de su propio valor de verdad -o referencial- por el que se diferencia de otros tipos de literatura" (3). Por otro lado, en el denominado "postestruturalismo": "La asimilación del realismo como valor al viejo concepto filosófico de la mímesis por parte de escritores como Foucault, Derrida, Lyotard o Deleuze, ha reformulado el debate entre realismo y modernismo en términos de un ataque platónico a los efectos ideológicos de la representación" (3-4). Este golpe postestructural deja al realismo en una posición incómoda: se trataría de un género impracticable, anacrónico, cuya fuerza política estaría destinada al fracaso en su ilusoria pretensión de realidad. La pregunta que surge, ¿se debe abandonar este género como una forma superada? ¿Qué puede entregarnos, todavía, el realismo? Si se quiere rescatar el realismo del anticuario de los géneros literarios se debe repensar una de las categorías centrales que su especificidad demanda: lo Real. ¿Cómo comprender lo real del realismo?

\section{Lo Real lacaniano}

La categoría de lo $\mathrm{Real}^{8}$ en Lacan tiene una especificidad que lo distancia del pensamiento postestructuralista ${ }^{9}$. El legado materialista del psicoanálisis lacaniano puede permitir darle otra vuelta de tuerca al realismo y

\footnotetext{
${ }^{7}$ En El efecto de realidad, Barthes denunciará la pretensión de realidad del realismo literario, reduciéndola a un efecto discursivo ilusorio. Según Barthes, el gran problema del realismo reside en su pretensión de frenar el deslizamiento del significante al anclarlo a un significado, empresa propia del género en la construcción del verosímil realista.

${ }^{8}$ Para Lacan, lo Real es lo que: “[...] no puede inscribirse sino como un impase de la formalización" (Seminario XX 112)

9 " A general term in the history of late twentieth-century thought that is used to designate, often dismissively, a wide range of discrete thinkers, including Barthes, Deleuze, de Man, Derrida, Foucault, Girard, and Said. The word was coined to refer to the intellectual movements that
} 
así reactivar su potencial estético y político. Desde esta perspectiva, se podría enmarcar el realismo argentino reciente en lo que Kornbluh (2017) denomina una "crítica literaria materialista contemporánea" (27). El realismo, desde este marco de comprensión, puede ser leído como "formalización creativa" de lo propiamente irrepresentable y no como mera imposibilidad referencial. Esta crítica literaria materialista que Kornbluh intenta reactivar -surgida de la relectura de Lacan que Žižek ha defendido desde El sublime objeto de la ideología (1989)- sostiene una postura no diferente a la del analista, en la que se propone una: "[...] curiosity about the Real, perspicuity about form, renunciation of mastery, and enthusiasm for the ironies of metadiscourse" (27). Kornbluh propone: "In the vein of these formalisms and asymptotic approaches to impasses, we might base a renewed Lacanian literary criticism on attending critically to the confluence of different levels of the Symbolic within a literary work and to the dynamics that seem to overdetermine or disrupt symbolizations" (36).

Este artículo tiene como finalidad delinear una crítica literaria materialista a partir de la noción lacaniana de lo Real, tomando como punto de partida algunas obras realistas argentinas de las últimas décadas: La villa de César Aira, Rapado y Este-oeste de Martín Rejtman y Rabia de Sergio Bizzio. Para ello, se expondrán el "materialismo" de Lacan y la diferencia entre este autor y el postestructuralismo. Estos dos puntos justifican, a nuestro parecer, la pertinencia de la teoría lacaniana hoy para los estudios literarios desde una perspectiva materialista.

Primero, se apuntala que no hay en Lacan el desarrollo sistemático de una suerte de "teoría del lenguaje". Es difícil extraer una continuidad lineal y progresiva que permita definirla con claridad. La ya extendida división de su obra en tres períodos: el periodo de lo Imaginario, el de lo Simbólico y

emerged from the International Colloquium on Critical Languages and the Sciences of Man, which was held at Johns Hopkins University in 1966" (Payne \& Rae 593). Para Derrida, en La estructura, el signo y el juego en las ciencias humanas, se trata de deconstruir los vestigios de la "presencia" metafísica aún operando en la noción de "estructura", para permitir el libre "juego" metonímico no anclado a la rigidez metafórica. Este sería un rasgo distintivo del llamado "postestructuralismo". De ahí que la "representación” y la "mímesis" sean blanco de críticas por parte de estos autores. 
el de lo Real, complejiza aún más las cosas (Žižek Television). Además, la sabida (y polémica) cuestión del estilo es ya otra dificultad para contornear una teoría del lenguaje en su pensamiento. El carácter anómalo de su corpus que, en realidad, se trata, por un lado, de textos orales -agrupados y editados como El Seminario por su yerno Jacques-Alain Miller- en los que el autor utiliza la posición del analizante para producir un efecto en su auditorio y, por otro lado, los Écrits que, como su nombre anuncia, son los textos que Lacan publicó, suman otro problema a la sistematización teórica. Como sugiere Žižek en Cómo leer a Lacan (2010), se deben leer los Seminarios en conjunto con los Escritos. Así: "Comúnmente, los seminarios oscilan, experimentan con diferentes perspectivas [...] Se trata de una temporalidad Nachträglichkeit (traducida crudamente como 'acción diferida'), propia de un análisis psicoanalítico: los Escritos son claros, proveen fórmulas precisas, pero sólo podemos entenderlos después de leer los seminarios que rellenan su background" (134).

Como es sabido, la obra de Saussure, Jakobson y Benveniste son particularmente importantes en el desarrollo del pensamiento lacaniano, sin embargo, el uso (o abuso) de los conceptos aportados por la lingüística difiere de las intenciones originales. De ahí que Lacan llamara lingüistería ${ }^{10}$ a su uso de la lingüística. En ella, el significante se distancia de su uso saussuriano ${ }^{11}$ : “QQué es el significante? -se pregunta Lacan- el significante -tal como lo

10 "Pero si se considera todo lo que, de la definición del lenguaje, se desprende en cuanto a la fundación de sujeto, tan renovada, tan subvertida por Freud hasta el punto de que allí se asegura todo lo que por boca suya se estableció como inconsciente, habrá entonces que forjar alguna otra palabra, para dejar a Jakobson su dominio reservado. Lo llamaré la lingüistería" (Lacan Seminario XX 24).

${ }^{11}$ La negación de toda sustancia o valor predeterminado en el lenguaje (Saussure) tuvo para el pensamiento moderno consecuencias importantes como, por ejemplo, la negación del realismo filosófico: "Si las palabras se encargaran de representar conceptos dados de antemano, de una lengua a otra tendrían correspondencias exactas para el sentido; pero no es así" (Saussure 9). En el esquema de Saussure hay una primacía del significado (concepto) por sobre el significante (dimensión sonora): "Si la parte conceptual del valor está constituida únicamente por las relaciones y las diferencias con los demás términos de la lengua, puede decirse otro tanto de su parte material. Lo que en la palabra importa no es el sonido mismo, sino las diferencias fónicas que permiten distinguir esta palabra de todas las demás, porque son ellas las que portan la significación" (6). Esta idea será critica por Derrida: "Que el significado sea originaria y esencialmente... huella, que esté desde el principio en posición del significante, tal es la proposición, en apariencia inocente, donde la metafísica del logos, de la presencia y de la conciencia debe reflexionar acerca de la escritura como su muerte y su fuente" (Derrida 39). 
promueven los ritos de una tradición lingüística que no es específicamente saussuriana $[\ldots]$ debe estructurarse en términos topológicos. En efecto, el significante es primero aquello que produce efectos de significado, y es importante no elidir que entre ambos hay una barrera que franquear" (27). Esta idea de la preeminencia del significante por sobre el significado (y de su separación fundamental) puede ejemplificarse con una referencia de Lacan a la obra de Freud:

[...] citaré el artículo de 1927 sobre el fetichismo, y el caso que Freud relata allí de un paciente para quien la satisfacción sexual exigía cierto brillo en la nariz (Glance auf der Nase), y cuyo análisis mostró que lo debía al hecho de que sus primeros años anglófonos habían desplazado en una mirada sobre la nariz (a glance at the nose, y no shine on the nose en la lengua "olvidada" de la infancia del sujeto) la curiosidad ardiente que lo encadenaba al falo de su madre, o sea, a esa carencia-deser eminente cuyo significante privilegiado reveló Freud (Lacan La instancia de la letra 489).

Este glance será el significante que, en su equívoco, construirá un significado para el sujeto. La fuerza del significante es índice de su materialidad sin significado: “[...] todo verdadero significante es, en tanto tal, un significante que no significa nada” (Lacan Seminario III 264) y: “[...] mientras más no significa nada, más indestructible es el significante" (265).

¿En qué sentido el significante es material? En La instancia de la letra, Lacan define la "letra" como: "[...] ese soporte material que el discurso concreto toma del lenguaje" (463) y luego añade "[...] esta simple definición supone que el lenguaje no se confunde con las diversas funciones somáticas y psíquicas que le estorban en el sujeto hablante. Por la razón primera de que el lenguaje con su estructura preexiste a la entrada que hace en él cada sujeto en un momento de su desarrollo mental" (463). Esta "otra escena" que el lenguaje es para el sujeto, que lo precede y ancla, supone que este está tomado por un resto material que lo descentra de su autopretendida unidad. De esto surge la dimensión ominosa de lo "no humano" del lenguaje mismo (Oyarzún 88) que el infantil ejercicio de repetir incesantemente una palabra evidencia.

Es esta preponderancia del significante la que haría insuficiente al realismo, a los ojos de Barthes. En la medida que el significante se desliza 
continuamente, la ilusoria pretensión de anclarlo a un significado estable, a través de la referencialidad, el realismo estaría condenado a una pobreza estética. Sin embargo, pretender que toda la fuerza estética del realismo radica en esta momentánea estabilidad sería más una miopía del crítico que una carencia de la obra literaria en sí misma. El realismo argentino de las últimas décadas demuestra, precisamente, como es la propia obra en su configuración significante la que desmonta la posibilidad de una estabilidad continua entre significante y significado. A través de una serie de recursos, el verosímil realista se ha desplazado a los tropiezos significantes, antes que a la mera referencialidad. En este sentido, el realismo de autores como Rejtman, Aira y Bizzio más que ser la escenificación de la imposibilidad del realismo, es la escenificación de la imposibilidad de la realidad misma de ser toda y coherente. Volveremos a estos autores.

Este materialismo que la obra literaria realista pondrá en acción, entonces, más que basarse en la mimesis representacional, estará en la inconsistencia misma que el significante revela respecto de la realidad. En este sentido, el materialismo no es simplemente nuestra inserción en la realidad objetiva. Žižek ejemplifica bien este punto refiriendo la tesis lacaniana sobre el cuadro Los embajadores de Holbein: "En el fondo de mi ojo, sin duda, se pinta el cuadro. El cuadro, es cierto, está en mi ojo. Pero yo estoy en el cuadro" 12 (Lacan Seminario XI 103). La primera parte ("el cuadro está en mi ojo") designa la subjetivación, la dependencia de la realidad en su constitución subjetiva; mientras que la segunda parte de la frase ("pero yo estoy en el cuadro"), provee la dimensión materialista propiamente tal: “[...] reinscribing the subject into its own image in the guise of a stain (the objectivized splinter in its eye)" (Žižek Parallax view 17). Por tanto, materialismo quiere decir que la realidad nunca es "toda", en ella hay siempre una "mancha" que indica nuestra inclusión en ella (17). Una realidad sin esta cualidad subjetiva, sería lo Real puro en su incoherencia absoluta, tal como lo muestra Rejtman en

\footnotetext{
${ }^{12}$ Un ejemplo casi literal de esta idea está en uno de los cortometrajes de la película los Sueños (1990) de Kurosawa: un visitante a una galería de arte al mirar detenidamente un cuadro de Van Gogh queda atrapado en él.
} 
Este-oeste, cuento al que volveremos.

La distinción entre significante y significado que opera en la obra de Lacan, supone la diferenciación entre lo Real y la realidad: “[...] lo real se distingue de la realidad. Esto, no para decir que sea incognoscible, sino que no es cuestión de entenderlo, sino de demostrarlo. Vía exenta de toda idealización" (Lacan Radiofonía 431). La realidad corresponde a las redes simbólicas e imaginarias que vehiculizan las coordenadas de nuestra existencia, mientras que lo Real es aquello irreducible al campo de la representación, pero que insiste y se manifiesta en las inconsistencias del funcionamiento de la realidad (Boothby 295). Lo Real, por tanto: “[...] does not exist, since it precedes language; Lacan reserves a separate term for it, borrowed from Heidegger: it "ex-sists" It exists outside of or apart from our reality" (Fink 25). Se mide por sus efectos, sus torsiones y fallas en el tejido de la realidad; su ex-sistencia se opone a lo que podría ser una versión de la "Cosa en sí" kantiana. Su diferencia radicaría en que: "[...] transcendental philosophy assumes the existence of pure limits of reality separated from an inaccessible real, whereas psychoanalysis begins from the hypothesis that the real irrupts within reality" (Cutrofello 170). El lenguaje, de acuerdo a esta perspectiva, no supone un una herramienta que permitiría la mediación entre lo Real inaccesible y la realidad, sino que se trata más bien de un trozo de lo Real con el que mediamos nuestros intercambios comunicativos. Los tropiezos de y en la realidad son lo Real en su ex-sistencia. En este sentido, la categoría del realismo literario puede ser repensada ya no como mera representación, sino como re-presentación, a saber, el modo en que se manifiesta el impase de la formalización de la realidad.

Como señala Tom Eyers (2011), al poner lo Real en la raíz de la lógica material del significante se comienza a percibir la "materialidad de lo inmaterial" y "la obstinada opacidad de lo material mismo" (157, traducción mía). Sin embargo, esta materialidad que se revela en el significante no debe ser tomada como una aproximación "anti-realista" o "hyper-textualista" (157), ni menos como la "materia" propia de la ciencia natural (164), pues el objetivo es precisamente desmontar la separación entre lo ideal y lo material. 
La materialidad del significante posee un estatuto paradójico. No se trata, entonces, de una visión materialista estándar, y este será precisamente el impase con el que Lacan se tropezará en sus últimos años tratando de encontrar un lenguaje que pudiera articular dicho carácter paradojal del significante ${ }^{13}$.

Una de las consecuencias de esta materialidad sin significado del significante ${ }^{14}$ es que subvierte la relación entre lo subjetivo y lo objetivo: la ilusión del yo, lugar en que el significado y el sentido son fijados, consiste en considerar que lo subjetivo está opuesto a lo objetivo, que el primero está "del lado del que habla, y que por lo mismo está del lado de las ilusiones: o porque deforma o contiene a lo objetivo" (Seminario III 265). Lo que el descubrimiento freudiano pone en evidencia, según Lacan, es que: “[...] lo subjetivo es algo que encontramos en lo Real" (266); Real no en un sentido de objetividad, sino más bien del equívoco del que el sujeto puede valerse gracias al significante (266). En otras palabras, se trata de la relación del sujeto con el inconsciente, de su inserción en la estructura simbólica significante que lo antecede. De ahí que Lacan establezca que:

No solo el lenguaje es un medio tan real como el mundo llamado exterior, sino que hay que estar tan cretinizado como uno lo está por las imaginaciones en las que se ha constituido hasta ahora la teoría del conocimiento y los métodos supuestamente concretos de educación, para eludir ese hecho masivo (pero justamente solo se convierte en un hecho una vez sostenido por una condición científica) de que el hombre crece -realiza su crecimiento-tan inmerso en un baño de lenguaje como en el medio llamado natural (Breve discurso en la ORTF 241).

Más adelante agrega: "Así, el fundamento de la historia marxista, a saber, la alienación introducida en el sujeto por la producción en cuanto tal,

\footnotetext{
13 " [...] the materialisation or objectification of the subject itself, the recognition of the status of the subject as elusive object in the visual field; the distribution of the subject, that is, between and over any subject/object opposition. References to topological figures abound in such theorisation precisely because the aim is to sneak past, around, or over the insistence on a symmetrical, or even asymmetrical divide between subject and object, between matter and logos" (Eyers 157).

${ }^{14}$ Como una pequeña digresión, habría que agregar el "mater" del materialismo, como escribió León Rozitchner en sus últimos ensayos: la unidad perdida con la carne materna, momento en que sueño y vigilia aún no estaban separados, insiste y se manifiesta en la ensoñación: "[...] aunque la "realidad" de los que solo sueñan cuando duermen conspire para olvidarla" (Rozitchner 10). El orden de los signos sepultará ese "mater" y el sujeto en su errancia intentará, en vano, restituir dicha unidad perdida.
} 
encuentra aquí un suplemento no menos materialista, en el sentido de que ninguna y simple intencionalidad, ninguna intención más o menos buena, es capaz de superar las volteretas de los efectos del inconsciente" (242). Habría, por tanto, un núcleo duro en el lenguaje que, al igual que en la historia marxista, alienaría al sujeto a una red de significaciones simbólicas que lo antecedería: el lenguaje sería una red autónoma con una lógica propia. Por tanto, lo que primaría en el lenguaje es el malentendido: entre lo Imaginario y lo Simbólico, entre nuestras ilusiones y los materiales significantes que nos sujetan, la comprensión contendría en su fundamento el desacuerdo ${ }^{15}$.

\section{Lacan y el postestructuralismo}

¿Por qué Lacan no sería un postestructuralista? ¿Cuál es la diferencia entre estas dos perspectivas y qué consecuencias tiene para la crítica literaria? Según Žižek, en el postestructuralismo hay una primacía de la metonimia por sobre la metáfora, es decir, la metonimia como figura de contigüidad, supone el deslizamiento permanente del sentido, la dispersión constante de la significación en el flujo textual; mientras que la metáfora, como figura de que reemplaza y fija una identidad, supone el intento de canalizar y estabilizar el movimiento metonímico (Žižek El más sublime de los histéricos 227). Para Lacan, por el contrario, la metáfora tiene un predominio lógico por sobre la metonimia, ya que es lo que totaliza el sentido y permite la significación: "La metáfora supone que una significación es el dato que domina y desvía, rige, el uso del significante, de tal manera que todo tipo de conexión preestablecida, diría lexical, queda desanudada" (Seminario III 313). El corte que la metáfora produce en el deslizamiento de los significantes es lo que estabiliza el sentido y asegura la relación estable entre significante y significado, lo que Lacan llamaba "el punto de almohadillado" (point de capiton) (Žižek El sublime objeto de la ideología 125; Lacan Seminario III 383). Derrida criticó esta idea

\footnotetext{
15 “¡Por Dios, me ha costado tiempo, pero qué bella es la lengua inglesa! ¿Alguien sabe aquí que, ya en el siglo XV, el slang hizo el hallazgo maravilloso de reemplazar a veces I understand you perfectly por I understumble perfectly? Lo escribo, porque quizás la fonetización no les haya permitido captar el matiz. Este understumble intraducible al francés incorpora al understand, que significa comprendo, el stumble, que quiere decir precisamente tropiezo. Comprender es siempre adentrarse dando tumbos en el malentendido" (Lacan, Seminario X 90).
} 
como una forma más de la "metafísica de la presencia": el intento de dominar la "diseminación" del texto, de otorgar a la falta un nombre (un significado), la castración. La respuesta de Žižek a esta crítica parte del paradójico enunciado "no hay metalenguaje". En la posición postestructuralista el enunciado equivale a decir que: "[...] el texto y el comentario del texto que supuestamente enuncia su verdad coinciden" (El más sublime de los histéricos 227), es decir, habría una continuidad entre teoría literaria y literatura. Su procedimiento consiste en la puesta en paréntesis de la pretensión de verdad del texto teórico y leerlo como literatura (227). Este procedimiento, demasiado cómodo a los ojos de Žižek, implica una posición de metalenguaje denegada: “[...] el esfuerzo de escribir poéticamente, de hacerle sentir al lector que nuestro propio texto está inmerso en un proceso que lo atraviesa, de evitar la forma puramente teórica y de apelar a procedimientos habitualmente reservados a la literatura no sirve más que para ocultar una toma de posición teórica neta" (228), es decir, un metalenguaje. Žižek toma una frase de Lacan para contraponer esta posición descomprometida subjetivamente: "Ahora bien, esto es precisamente lo que quiero decir y lo que digo, pues lo que quiero decir, lo digo..." (Seminario $X I$ 198). La paradoja de este enunciado, que parece eliminar la distancia que separa lo que se quiere decir y lo dicho efectivamente, da cuenta de una: "[...] imposibilidad encarnada" que: "[...] mantiene abierta la diferencia fundamental del proceso significante e impiden recaer en la posición del metalenguaje" (El más sublime de los histéricos 229).

Por tanto, más que ser una teoría que cierra el deslizamiento significante en nombre de un significante trascendental, es más bien una teoría material que pone en operación el equívoco: contra la ilusión de una comprensión plena, de una legibilidad absoluta, es decir, lo que el propio Lacan intentó poner en juego en su escritura. Textos que hacen tropezar la comprensión y cuyo efecto está en la interrupción de la cadena asociativa que se le arroga predeterminadamente a un texto: “[...] lo escrito no es para ser comprendido. Por esto, precisamente, nadie está obligada a comprender los míos. Si no los comprenden, tanto mejor, pues tendrán así la oportunidad de explicarlos" (Seminario XX 46). De ahí que 
el malentendido sea la base del discurso interhumano (Lacan Seminario III $233)^{16}$.

En este sentido, se desprenden para la crítica literaria dos maneras de abordar un género como el realista: por un lado, una perspectiva postestructuralista sancionaría la imposibilidad de todo texto realista de dar cuenta de la realidad tal como es, afirmaría la imposibilidad de bordear lo real y, por tanto, la impracticabilidad de cualquier empresa realista que no tome en cuenta esta impasse. El realismo reciente sería, tan solo, la prueba fidedigna de un fracaso de la representación. Por otro lado, de manera contraria, desde una perspectiva materialista -tal como la hemos entendido aquí-, podría plantearse que el realismo siempre ha estado preso de esta imposibilidad, pero, al contrario del postestructuralismo, esta imposibilidad es de la realidad misma, su torcedura constitutiva. Lo que el realismo hace es presentar esta imposibilidad, mapear las coordenadas de lo que no cuaja en la realidad, mostrar su inconsistencia fundamental, y no una representación de la realidad tal cual es.

\section{Nuevos realismos en la narrativa argentina reciente: Este-oeste de Martin Rejtman, La villa de César Aira y Rabia de Sergio Bizzio}

El cuento largo Este-oeste de Martín Rejtman puede leerse en esta clave. Su "realismo idiota"17 (Speranza 2015), parece responder al mandato ético de la imposibilidad de simbolizar lo real (Kornbluh 34) casi de manera literal. Este-oeste narra/describe la cotidianeidad de una familia argentina que

\footnotetext{
${ }^{16}$ Respecto de los malos entendidos, quedaría pendiente examinar para la teoría materialista del lenguaje la famosa "antifilosofía" de Lacan. Evidentemente no se trata de una mirada peyorativa sobre el quehacer filosófico, ni que el saber que la filosofía elabora sea insuficiente o falso. Se trata más bien de una denuncia a la posición enunciativa que históricamente ha ocupado el discurso de la filosofía: el del discurso del Maestro [maître] opuesto al de la ética del discurso del analista (Lacan Seminario XVII).

${ }^{17}$ Speranza acuña esta categoría a partir de la noción de lo real de Rosset: “[...] ontología de lo real centrada en su carácter insólito, singular, único, incognoscible, sin espejo y sin doble, esto es -y de ahí el título del tratado-, en su carácter idiota. En su etimología primera, aclara Rosset, idiota significa 'simple, particular, único', y solo después, por una extensión semántica, 'persona privada de inteligencia, ser desprovisto de razón'. De ahí que para Rosset todas las cosas, todas las personas son en su sentido primigenio idiotas: no existen más que en sí mismas y son incapaces de aparecer de otro modo que allí donde están y tales como son (Speranza 7). No es, claramente, la noción de lo Real que hemos descrito hasta aquí.
} 
pasa unos días en Chile. Se divide en dos capítulos: el primero "desarrolla" una serie de microacontecimientos sin ningún tipo de ilación interna o entramado profundo. En el segundo, en cambio, el relato se focaliza en la mirada de Esteban, quien viaja a Estados Unidos, lugar en el que enfrenta una serie de obstáculos que lo obligan a desplazarse constantemente entre distintas ciudades. Adviértase que esta síntesis desde ya conlleva un corte textual, una ilación de sentido inevitable. El efecto del texto es profundamente ominoso en cuanto nos devuelve la realidad decantada de todo encuadre explicativo: se trata de una realidad insignificante, de un entramado narrativo repleto de detalles sin sentido. Abundan en el cuento enunciados del tipo: "La conversación es poco fluida y ninguno de los dos hace ningún esfuerzo. Al fondo, detrás de la cortina de lluvia, se alcanzan a distinguir las montañas" (Rejtman 52). El narrador evita cualquier explicación de corte sociológico, psicológico, filosófico, etc., se limita a una descripción de los acontecimientos sin ningún tipo de marco temático mayor.

Tanto el narrador como el personaje suspenden toda posibilidad de juicio sobre la realidad. Suspensión que se dilata ad infinitum. La realidad, en el entramado del cuento, parece constreñir toda posibilidad de pronunciamiento subjetivo debido a su carácter difuso e irreal: "El agua está quieta y Esteban se da cuenta de que no era consciente de la existencia de un animal así. Relajado como está se pregunta si es real, si todo lo que lo rodea es real, si él mismo es real" (Rejtman 95). También en las imágenes que dan a los acontecimientos una superficie cinematográfica, exagerada y ridícula:

A lo lejos, entre el polvo, ve a un hombre y una mujer muy altos que parecen
supervisar trabajos de remodelación. Podrían ser personajes de una película de
ciencia ficción [...] Más de cerca puede confirmar que el aspecto fibroso y el
bronceado de esa gente tienen algo de sobrenatural: como si hubieran tomado sol y
hecho ejercicio todos los días de todos los años de sus vidas (68).

Junto a este pasaje, cabe mencionar: "Tan milimétrica es la simultaneidad que es imposible decir qué vino primero, el comentario o la acción” (80), y: “de a ratos da la sensación de que lo que hacen y lo que dicen está perfectamente ensayado" (84). Estos efectos de irrealidad que este el texto ofrece, funcionan 
como indicios de algo que ha quedado forcluido ${ }^{18}$.

La obra de Rejtman parece ser justamente una suerte de obliteración total de lo Real ${ }^{19}$, es decir, la imposibilidad de simbolizarlo: un mundo de azar, de eventos completamente contingentes, sin ningún tipo de punto de almohadillo que permita metaforizar los eventos que ocurren. Leído en clave referencial o representativa, Este-oeste parece conducir a la tesis obvia de la imposibilidad del realismo ${ }^{20}$, la dificultad de construir una narrativa que totalice el sentido de la realidad: no hay ilusiones que permitan construir una narrativa. Ahora, ¿puede el realismo sobrevivir si se vacía de esta supuesta obsesión con la referencialidad? Pensado el realismo con la noción de lo Real que hemos descrito, su lectura debería ser más en el orden de la "formalización creativa" que en el de la representación. Esta última solo lleva al atolladero de la "ilusión referencial" (Barthes 218). Por tanto, leído el texto en clave formal, este parece apuntar otras cualidades del realismo: una que performa la imposibilidad de prescindir de lo Real. En las coordenadas ideológicas imperantes, en las que hay un decaimiento de la función de "mapeo cognitivo"21 (Jameson 2014), el único realismo posible pareciera ser este: un mundo de

\footnotetext{
${ }^{18}$ Lacan define este término del siguiente modo: "Lo reprimido siempre está ahí, y se expresa de modo perfectamente articulado en los síntomas y en multitud de otros fenómenos. En cambio, lo que cae bajo la acción de la Verwerfung tiene un destino totalmente diferente... la Verwerfung y la alucinación, vale decir la reaparición en lo real de lo rehusado por el sujeto" (Lacan Seminario III 24-25). Después añade: “[...] a la noción de Verwerfung de la que partí, y para la cual, luego de haberlo reflexionado bien, les propongo adoptar definitivamente esta traducción que creo la mejor: la forclusión" (456). Forclusión tiene dos sentidos: "1) En derecho: vencimiento de una facultad o derecho no ejercido en los plazos prescritos. 2) Figurativamente: exclusión forzada, imposibilidad de entrar, de participar" (457).

${ }^{19}$ Cabría mencionar una de las películas de Rejtman que desarrolla la misma idea: Rapado (1996). Al inicio del filme le roban la motocicleta y los zapatos al protagonista, pero, a diferencia de El ladrón de bicicletas (1948) de Vittorio de Sica (la que sería una referencia intertextual), este hecho no desemboca en ningún intento de recuperación, ninguna épica de la búsqueda: el fracaso está inscrito en el momento mismo del robo. Parece estar sujeto a un puro azar, una irrupción pura de lo Real sin sentido.

${ }^{20}$ Véase el texto de Roland Barthes "El efecto de realidad". En él, Barthes sostiene que el realismo está sujeto a una "ilusión referencial", producto de su obsesión con lo concreto y objetivo: "La verdad de esta ilusión es esta: eliminado de la enunciación realista a título de significado de denotación, lo 'real' retoma a título de significado de connotación; pues en el mismo momento en que esos detalles se supone que denotan directamente lo real, no hacen otra cosa que significarlo, sin decirlo" (218).

21 “A diferencia del concepto familiar de alienación, un proceso que atañe a la actividad y en particular al trabajo (disociar a los trabajadores de su trabajo, su producto, sus compañeros, y, en última instancia, de su propio "ser específico"), la cosificación es un proceso que afecta
} 
significaciones flotantes sin ningún corte metafórico mayor que fije alguna identidad.

Rejtman nos confronta con lo que Todd McGowan llama "the bizarre nature of normality", a propósito de las películas de David Lynch: "Ironically, the films seem bizarre to us precisely because of the excessiveness of their normality [...] Lynch reveals how the bizarre is not opposed to the normal but inherent within it" (McGowan 12). Tanto Este-oeste como Rapado escenifican este exceso de normalidad, la extrañeza de la realidad sin la mediación de la fantasía. Por tanto, la fuerza crítica del realismo de Rejtman residiría en su posibilidad de presentar, formal y negativamente, el tejido ideológico. Contra la lectura posmoderna que el texto podría sugerir, habría que contraponer la siguiente frase de Pessoa del Libro del desasosiego: "Sin ilusiones, vivimos tan sólo del sueño, que es la ilusión de quien no puede tener ilusiones" (25), pero con una pequeña variación paradigmática: "Sin ilusiones, vivimos tan sólo de la realidad, que es la ilusión de quien no puede tener ilusiones".

En La villa, Aira elabora un texto realista que parece depender intrínsecamente del delirio. En la novela, el acceso a la villa -la promesa realista tradicional, si se quiere- es indefinidamente pospuesta. Se trata de un espacio clausurado cognitivamente para el lector: "Esta ciudad de la pobreza dentro de la ciudad podía obedecer a sus propias leyes" (Aira 33). El centro de la villa es un misterio que la novela no revelará. Este centro ausente está bordeado de irrealidad y delirio, trama que constituye la novela.

La historia se focaliza en Maxi, personaje central, representante de una clase media relativamente acomodada, ayuda voluntariamente a los cartoneros y cirujas a transportar sus cargas. Este personaje parece encarnar la promesa de un acceso a la villa, pero que solo lo logrará a través del sueño: se queda dormido en las cercanías de la villa y es transportado a esta. En paralelo, la novela nos presenta la trama de un asesinato de una joven. El padre de la

nuestra relación cognitiva con la totalidad social. Es una enfermedad de esa función de mapeo por medio de la cual el sujeto individual proyecta y modela su inserción en la colectividad" (Jameson 536). 
asesinada tiene el mismo nombre que un policía corrupto que más tarde es baleado por la policía:

Era una casualidad verdaderamente asombrosa, sobre todo porque ni el nombre ni el apellido eran tan comunes. Se habría sorprendido muchísimo de enterarse de que existía otro Ignacio Cabezas; pero que encima ese homónimo viviera en el Bajo de Flores, en su radio de acción, y que se diera a conocer públicamente de este modo, superaba toda previsión, y bastó para que le sugiriera la presencia de un mecanismo en el que él podía jugar un papel, no sabía cuál todavía (Aira 44).

Ignacio Cabezas, el detective corrupto, busca en la villa una droga llamada proxidina (droga ficticia), cuya cualidad es la de acercar las cosas. El personaje es perseguido por la policía hacia el final de la novela y es baleado. Toda la persecución es abordada de un modo delirante, en el que la realidad apenas mantiene su consistencia: "En los canales la actividad era frenética. Ya habían encontrado fotos de Cabezas en sus archivos digitalizados, y las estaban intercalando en la emisión en vivo. Era una cara horriblemente deformada por la electrónica, una cara sin explicación. Cada segundo que permanecía en la pantalla se deformaba más" (163).

Si bien algunos críticos han enfatizado el carácter delirante de la obra airiana, habría que pensar qué aporta el delirio a su realismo. Afirma Speranza: "Atravesado el límite, la trama, improvisada e informe, devora los fragmentos de realidad, los confunde con sus dobles televisivos, y los tritura en su ya ejercitada máquina voraz que, con movimiento centrífugo y entrópico, destruye el verosímil y el sentido, y los aplana en una superficie colorida de cuento de hadas desquiciado" (5).

Quizás otra manera de plantearlo sería que, más que el delirio devore los fragmentos de la realidad, este es yuxtapuesto a la realidad, lo que produce un cortocircuito y nos presenta los contornos fantásticos de la propia realidad. Más que decir que "la realidad es delirio" en Aira, lo que La Villa parece hacer es mostrar cómo la realidad debe estar contorneada por lo fantástico o delirante, y viceversa. Esta idea se justifica en la propia concepción que Aira tiene sobre el realismo: "[...] el realismo se infiltra hasta por las grietas más delgadas de la magia" (Aira El realismo 256). Para Aira, es la magia, el delirio 
y/o el sueño el que demanda "realidad": requiere de ella para estructurarse en cuanto tal. Es en esta inconsistencia que Aira logra hacer operar en su relato en que se nos revela lo Real de su realismo: es decir, la interdependencia de realidad y fantasía.

En este sentido, el realismo que Aira elabora en su novela consiste en el intento de encuadrar en un mismo plano delirio y realidad, en una continuidad que no se resuelve en el texto, a través de una serie de simetrías y situaciones anómalas: "La veía todos los días, en el espejo que tenía en la pared frente a la cama $[. .$.$] y siempre había supuesto que era una especie de aberración del$ cristal del espejo" (Aira La villa 87). Aquella figura era en realidad una mujer que se proyectaba de casualidad en el espejo, pero para Maxi: “[...] ella había salido del espejo, para hacerle una advertencia. Quería protegerlo..." (87).

Del mismo modo en que Aladino necesita de la realidad para estructurar la magia (Aira, El realismo 251), el realismo debe incluir la realidad para estructurar el delirio. La realidad y lo fantástico están dispuestos al modo de una cinta de Möebius. Como señala Sager, comentando la conferencia de Aira: “Ese es el giro decisivo de 'El realismo' porque es a la vez una intrusión en la biblioteca borgiana, una transformación de las filiaciones y genealogías tradicionales de la historia de la literatura y también del orden (tal vez residual pero persistente) establecido por las teorías literarias que sostienen el corte inconciliable entre el realismo y la potencia del deseo, la fantasía y la magia" (Sager 83).

Finalmente, en Rabia de Sergio Bizzio encontramos el rol de las mediaciones en la construcción de la realidad. Si bien Bizzio toma ciertos significantes propios del realismo social y comienza con la articulación de un conflicto de clases, el juego de mediaciones que realiza permite una operación que no se reduce a mostrar la clásica alienación de las clases populares, sino más bien desde la reificación de la realidad, la fractura de la función de "mapeo cognitivo" (Jameson 12).

La historia trata de José María, un trabajador de la construcción que tiene una enamorada, Rosa, sirvienta en la mansión de los Blinder, una familia burguesa acomodada. En un arranque de rabia, el protagonista termina 
matando al capataz de la construcción y se esconde en la casa de los Blinder. Desde ese momento, José María vive escondido de la sociedad en una de las habitaciones de la mansión. Desde allí, llama por teléfono a Rosa cada día, quien vive en otra de las habitaciones de la gran mansión, y la espía durante el día. Poco a poco el espacio se vuelve alienante y asfixiante, hasta desembocar en un final trágico.

El espacio narrativo que Bizzio construye está profundamente marcado por una serie de mediaciones que hacen de los personajes habitantes fantasmagóricos: "Sus prevenciones, combinadas con su agilidad natural lo hacían desplazarse en la oscuridad con la sutileza de un fantasma. Más que un fantasma, en realidad, parecía una imagen de cine mudo proyectada hacia afuera de la pantalla" (48). A lo largo de la obra, el narrador insiste en la homología entre el espacio de la narración y la metáfora visual: "cerró la ventana y, como si la ventana fuera el obturador de una cámara fotográfica, repasó la imagen grabada en sus retinas" (61).

Este juego de mediaciones que produce un ambiente profundamente atravesado por lo imaginario llega al punto de establecer un sutil intertexto con La invención de morel de Bioy Casares: “¿Sabía quién era Rosa? No. En cierto sentido, la había inventado" (141). Este espacio al interior de la casa es planteado como si se tratase de una proyección. Al igual que en Aira, la construcción de la realidad parece supeditada a lo imaginario, pero lo que la novela produce es un conjunto de relaciones intervenidas, otorgándoles una dimensión fantasmática:

Sus prevenciones, combinadas con su agilidad natural, lo hacían desplazarse en la oscuridad con la sutileza de un fantasma. Más que un fantasma, en realidad, parecía una imagen de cine mudo proyectada hacia afuera de la pantalla, una imagen familiarizada con las distancias, provista de un radar extra que en los momentos de distracción, cuando estaba a punto de llevarse por delante un florero o de tropezar con el borde de un alfombra, lo alteraba y hasta parecía desmaterializarlo o disolverlo (48).

El mundo narrativo se va transformando en un mundo espectral, de objetos visuales que se ofrecen a la vista casi sin sustancia. José María ocupa el lugar de un espectador trágico que, atrapado en su condición fantasmática, 
no puede interactuar con los demás sino solo por medio de un teléfono. Dice el narrador "Lo que no soportaba era oírla sin verla, y verla sin ser visto" (78).

Rabia, bajo el esquema propio de la telenovela (Ledesma 81), dispone un conjunto de personajes en un espacio que produce relaciones totalmente reificadas. Por reificación se entiende: “[...] el proceso que afecta a nuestra relación cognitiva con la totalidad social [...] una enfermedad de la función cartográfica por medio de la cual el sujeto individual proyecta y modela su inserción en la colectividad" (Jameson 12). Por tanto, lo Real de la realidad en la novela de Bizzio es esta disposición formal del espacio que escenifica la reificación de las relaciones sociales. Más que representar la realidad, Rabia produce esta falla de mapeo en la mansión de los Blinder, alegoría del espacio social.

\section{Conclusión}

Lo que se ha desarrollado en este artículo es una descripción explorativa de lo que podría catalogarse como una teoría materialista de lo Real lacaniano -la luz de la lectura de Slavoj Žižek- y se ha propuesto una relectura del realismo como categoría estética, más allá del impasse postestructuralista, a saber, la impracticabilidad del realismo y la denuncia de su ilusoria pretensión referencial. Para ello, se han planteado algunas de las tesis centrales del psicoanálisis lacaniano para así mostrar su deslinde con la teoría postestructuralista. Esto ha permitido revaluar el vínculo entre psicoanálisis y literatura, en la medida en que lo que está en juego lingüísticamente en la literatura no es su posibilidad referencial o de comprobación de esquemas psicoanalíticos predeterminados, sino una operación formal de lidiar con la realidad, lo Real y su simbolización imposible. En el caso de Rejtman, el significante forcluido es, precisamente, la realidad, es decir, la consistencia simbólico-imaginaria de nuestra experiencia del mundo retorna en lo Real de manera ominosa. En Aira, la continuidad entre delirio y realidad configuran una cinta de Möebius, pues como el propio autor señala sus reflexiones acerca del realismo: “[...] el realismo no debe parecer realista para acercarse más a la realidad, debe parecerse más bien a un juego de geometrías ingeniosas" (254), 
en otras palabras, no hay una realidad que el realismo fracasa en representar debido a su insuficiencia referencial, sino que solo podemos captar la realidad - la constitución mágica, fantasiosa o delirante de la realidad-a través de estas deformaciones que el realismo nos presenta. Es a través de estos juegos de geometrías ingeniosas en que lo Real del realismo emerge. En Bizzio, la trama social es dispuesta en un juego de mediaciones producidas por el espacio asfixiante de la casa burguesa: a través de la construcción del espacio, Bizzio produce la realidad de la reificación, y presenta la inconsistencia de la realidad social.

\section{Referencias}

Aira, C. "El realismo". Realismo, cuestiones críticas. Cuadernos del seminario 2 (comp. Sandra Contreras). Rosario: Centro de Estudios de Literatura Argentina y Humanidades y Artes Ediciones - H. y A. Ediciones, 2013.

Aira, C. La villa. Buenos Aires, Buenos Aires: Emecé, 2001.

Barthes, R. "El efecto de realidad". El Susurro del Lenguaje. Barcelona: Paidós, 1987.

Bizzio, S. Rabia. InterZona: Buenos Aires, 2004.

Boothby, R. Freud as Philosopher, New York: Routledge, 2001.

Contreras, S. Realismo, cuestiones críticas. Cuadernos del seminario 2 (comp. Sandra Contreras). Rosario: Centro de Estudios de Literatura Argentina y Humanidades y Artes Ediciones - H. y A. Ediciones, 2013. 
Cutrofello, A. "The Ontological Status of Lacan's Mathematical Paradigms". Reading Seminar XX: Lacan's Major Work on Love, Knowledge, and Feminine Sexuality (eds. Suzanne Barnard y Bruce Fink). New York: SUNY Press, 2002.

Derrida, J. De la gramatología. Buenos Aires: Siglo XXI Editores, 1970.

Dolar, M. "I Shall Be with You on Your Wedding-Night: Lacan and the Uncanny" Rendering the Real, Vol. 58, 1991, pp. 5-23. Disponible en: http://www.jstor.org/stable/778795. Consultado el 15 de Enero de 2018.

Eyers, T. "Lacanian Materialism and the Question of the Real". Cosmos and History: The Journal of Natural and Social Philosophy, vol. 7, no. 1, (2011): 155-166.

Fink, B. The lacanian subject: between language and jouissance, New Jersey: Princeton University Press, 1995.

Freud, S. "Lo ominoso". Obras completas. Tomo XVII, Trad. José L. Etcheverry. Buenos Aires: Amorrortu editores, 1992.

Jakobson, R. "Sobre el realismo artístico". 1965. Teoría de la literatura de los formalistas rusos. Trad. Ana María Nethol. Buenos Aires: Siglo XXI Argentina Editores, 1976.

Jameson, F. "El debate entre realismo y modernismo. Reflexiones para concluir". Youkali. 189-201.

Kornbluh, A. "Reading the Real: Žižek's Literary Materialism”. Everything You Always Wanted to Know about Literature but Were Afraid to Ask Žižek (ed. Russell Sbriglia). Duke University Press, 2017. 
Lacan, J. "Seminario sobre La carta robada". Escritos I. 1966. Trad. Tomás Segovia y Armando Suárez. Buenos Aires: Siglo XXI Editores, 2013.

Lacan, J. "La instancia de la letra en el inconsciente o la razón desde Freud". Escritos I. 1966. Trad. Tomás Segovia y Armando Suárez. Buenos Aires: Siglo XXI Editores, 2013.

Lacan, J. Seminario III: La psicosis. 1955-1956. Trad. Diana Rabinovich \& Juan Luis Delmont-Mauri. Buenos Aires: Paidós, 2013.

Lacan, J. Seminario XI: Los cuatro conceptos fundamentales del psicoanálisis. 1964. Trad. Juan Luis Delmont-Mauri \& Julieta Sucre. Buenos Aires: Paidós, 2010.

Lacan, J. Seminario XX: Aún. 1973. Trad. Diana Rabinovich, Delmont-Mauri y Julieta Sucre. Buenos Aires: Paidós, 2009.

Lacan, J. "Breve discurso en la ORTF". 1966. Otros escritos. Trad. Graciela Esperanza et al. Buenos Aires: Paidós, 2012.

Lacan, J. "Radiofonía". 1970. Otros escritos. Trad. Graciela Esperanza et al. Buenos Aires: Paidós, 2012.

Ledesma, G. "Literatura y televisión en Rabia de Sergio Bizzio". Revista de Lengua y Literatura, 2014: 79-85.

Marx, K. La ideología alemana. Trad. Wenceslao Roces. Barcelona: Grijalbo, 1974.

McGowan, T. The impossible David Lynch. New York: Columbia University Press, 2007. 
Nietzsche, F. "Über Wahrheit und Lüge im außermoralischen Sinn". En Werke in drei Bänden (ed. Schlechta), traducción al español de Pablo Oyarzún, III, 309-322, München: Hanser, 1966.

Oyarzún, P. "La cuestión de lo siniestro en Freud”. Revista de Teoría del Arte, Tomo VIII, Universidad de Chile, 2003.

Payne, M \& Jessica R. B. "Poststructuralism". A Dictionary of Cultural and Critical Theory (second edition). West Sussex: Blackwell Publishing, 2010.

Pessoa, F. El libro del desasosiego. Barcelona: Seix-Barral, 2011.

Poggiese, D. "Discusiones en torno al Realismo en las generaciones jóvenes del primer postperonismo". III Jornadas Hum. H. A.: Representaciones e identidades, 2009.

Rejtman, M. "Este-oeste”. En Tres cuentos. Buenos Aires, Mondadori, 2013.

Rozitchner, L. Materialismo ensoñado. Buenos Aires: Tinta Limón Ediciones, 2011.

Sager, V. "La garantía de la lógica El realismo de Aira y la magia de Borges". Realismo, cuestiones críticas". Cuadernos del seminario 2 (comp. Sandra Contreras). Rosario: Centro de Estudios de Literatura Argentina y Humanidades y Artes Ediciones - H. y A. Ediciones, 2013.

Saussure, F. Curso de Lingüistica general. Madrid: Fontamara, 1993. 
Speranza, G. "Por un realismo idiota". Revista Otra Parte, n 8, 2006. Disponible en: http://www.revistaotraparte.com/n\%C2\%BA-8oto\%C3\%B1o-2006/por-un-realismo-idiota. Consultado el 16 de Enero de 2018.

Žižek, S. El sublime objeto de la ideología. 1989. Trad. Isabel Vericat Nuñez. Buenos Aires: Siglo XXI, 2005.

Žižek, S. Parallax View. London: MIT, 2006.

Žižek, S. Cómo leer a Lacan. 2006. Trad. Fermín Rodríguez. Buenos Aires/ Barcelona/México: Paidós, 2010.

Žižek, S. El más sublime de los histéricos. 2011. Trad. Alcira Bixio. Buenos Aires: Paidós, 2013.

Žižek, S. The Lacanian Real: Television. The Sympton 9. Disponible en: http://www.lacan.com/symptom/the-lacanian.html. Consultado el 16 de Enero de 2018. 